\title{
Designing Extended Assignments for Team-Based Learning Modules
}

\author{
Antony J. Hodgson and Peter Ostafichuk \\ Department of Mechanical Engineering \\ University of British Columbia
}

\begin{abstract}
The design block in UBC's new integrated second year curriculum is taught using a team-based learning approach in which students work in teams of six or seven. The course is composed of six modules, each comprised of a reading assignment, a readiness quiz, $\sim 5$ tutorials and $\sim 12$ class hours. Much of the class time is devoted to extended assignments through which students integrate their knowledge, apply their skills, and make judgments which they then defend in class. We have found that designing appropriate and effective assignments has been one of the most difficult aspects of TBL for us to master. In this paper, we present examples of what we have tried over the past two years and assess their strengths and weaknesses.
\end{abstract}

\section{Introduction - The Mech 2 Program}

In 2004, the Department of Mechanical Engineering at the University of British Columbia (UBC) introduced an innovative new program in engineering education. The program, known as Mech 2, is a carefully designed approach aimed at developing the analytical, practical, and design skills of second year mechanical engineering students. Mech 2 is taught by a team of 17 instructors and almost 50 teaching assistants, and it is fully integrated in content and delivery. It completely replaces a conventional course-based curriculum for the approximately 128 second-year mechanical engineering students at UBC.

The Mech 2 course sequence begins in the first semester with MECH 220, a four-week technical skills practicum. This practicum includes hands-on instruction in machining, computer-aided design (CAD), electronics, and drawing. The students next take MECH 221, a ten-week engineering science course in dynamics, solid mechanics, electrical circuits, materials engineering, and differential equations. After a two-week university break, the second semester starts and students go on to take the first part of a seven-week course in engineering design, MECH 223. The first part of MECH 223 is four weeks in duration and has a design project focused on the material of MECH 221. MECH 222, a seven-week engineering science course in thermodynamics, fluid mechanics, and multi-variable calculus, follows the first part of MECH 223. Finally, the second part of MECH 223, with a focus on the design of a thermo-fluid system, completes the last three weeks of the year. APSC 201, a course in technical communications, is separate from Mech 2 for accreditation reasons, but is otherwise fully integrated with the MECH 223 design course.

The MECH 223 course combines the practical elements of MECH 220 with the engineering science of MECH 221 and MECH 222 and it introduces students to a formal design process. Because it is a design course, it is structured somewhat differently from the more analytical courses. These differences pose interesting challenges in course design, but before describing these challenges in detail, we first outline the structure and syllabus of the MECH 223 course.

\section{Course Structure and Syllabus}

The MECH 223 course is delivered using a teambased learning (TBL) approach adapted from Michaelsen, Knight, and Fink [1]. Details of the application of the TBL methodology towards the development of MECH 223 are presented in [2]. The highlight of each part of MECH 223 is an intensive design project (common to the entire class) that concludes with a competition. The projects create a focus and a context for the course material but instruction primarily comes from classes, tutorials, labs, workshops, readings, and quizzes.

A sample timetable for a typical week in $\mathrm{MECH}$ 223 is shown in Figure 1. The primary contact between instructors and students is in the classes, which include a mix of mini-lectures and in-class team exercises. Teaching assistant-lead tutorials and computer labs are used to introduce class topics and give students an opportunity to develop design skills by working through simple problems. Each week, students work on project specific tasks during two design meetings, one construction lab, and one 
assembly lab. Two classes on technical communication and a special event on Thursday complete the week.

\begin{tabular}{|c|c|c|c|c|c|}
\hline \multicolumn{6}{|c|}{ Sample MECH 223 Weekly Schedule } \\
\hline & MON & TUES & WED & THUR & FRI \\
\hline 8 & Tutorial & Tutorial & Tutorial & & Tutorial \\
\hline 9 & Meeting & & Meeting & & Tech Comm \\
\hline 10 & Class & Class & Class & Field trip, & Class \\
\hline 11 & Class & Class & Class & special & Class \\
\hline 12 & & Class & & & \\
\hline 1 & Class & Tech Comm & Class & & Class \\
\hline 3 & Const. Lab & & $\begin{array}{c}\text { Assembly } \\
\text { Lab }\end{array}$ & & $\begin{array}{c}\text { Computer } \\
\text { Lab }\end{array}$ \\
\hline
\end{tabular}

Figure 1. Sample MECH 223 weekly schedule

The course topics are divided between six modules, each comprised of roughly eight to twelve lectures. These topics are summarized in Table 1.

\section{Table 1. Course Topics}

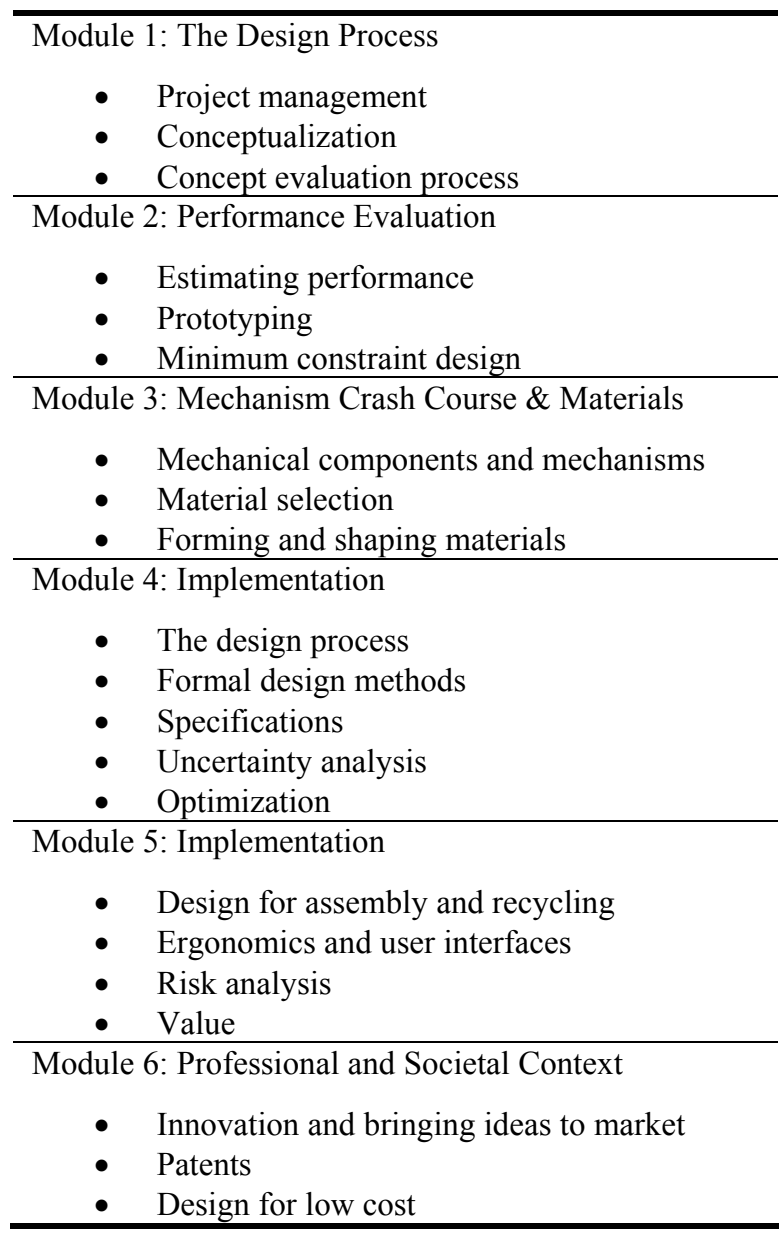

Each module is roughly $1-1.5$ weeks in length. The first three modules occur in the first part of the course with the first project, and the last three occur in the second part of the course with the second project. The topics in the first half of the course are arranged so that the students get the information required to begin their first project immediately at the start of the course. The modules in the second half of the course re-examine the design process in greater depth, providing additional tools and context for the students.

Each of the six modules follows the TBL framework outlined in [1] and [2]. Specifically, each module begins with a reading exercise assigned approximately one week prior to the start of the module. In the first class of the module, the students write an individual "readiness assessment process" (RAP) quiz on the readings. Immediately following the individual quiz, the students repeat the quiz but this time in their project teams; in the team quiz, students are encouraged to discuss and debate the questions with their teammates. After reviewing individual and team performance on the quiz, instructors lead a feedback session and answer any outstanding student questions. The entire RAP process, from individual quiz through feedback, takes approximately 60 minutes.

The remaining classes in a module are used for a combination of in-class exercises and short "minilectures". These classes are the primary contact between instructors and students. Daily teaching assistant-lead tutorials precede the classes and they provide students with a chance to work through simple examples of the types of problems they will explore further in class.

Where possible, each module concludes with a large-scale problem that encompasses and integrates many of the topics of that module. This "assignment arc" requires that students apply much of the knowledge, skills, and judgment that they have developed through the preceding tutorials and classes. The assignment arc culminates on the last class of the module with a classwide discussion and debriefing. Students are expected to apply their experiences in the assignment arc towards the course project.

This process, from the RAP quiz through to the Assignment Arc debriefing is shown schematically in Figure 2. 


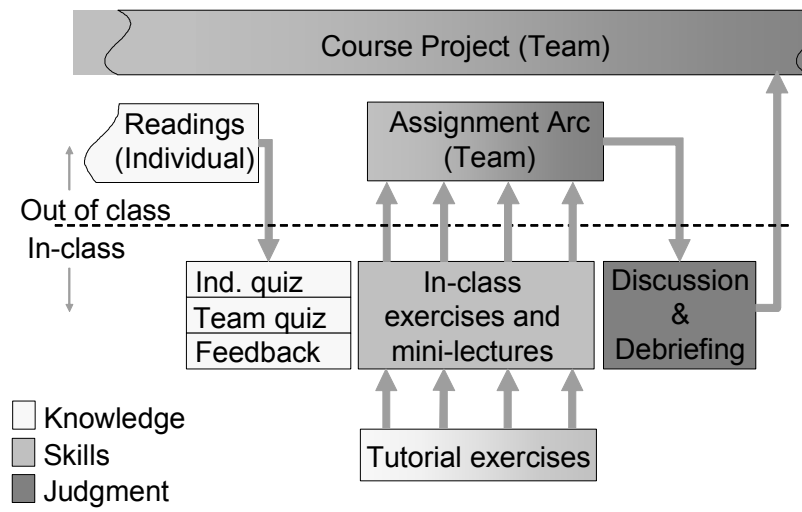

Figure 2. Module Structure Schematic

\section{Learning Taxonomy}

Activities in the MECH 223 course are designed with a three-stage learning taxonomy in mind: students must first acquire basic knowledge, then develop skills to use and apply that knowledge, and finally develop the judgment required to know the limitations of the various skills and when to select one skill or approach over another. This knowledge-skills-judgment taxonomy is similar to the six-stage taxonomy first proposed by Benjamin Bloom and commonly known as "Bloom's Taxonomy of Learning Domains" [3]. The levels in Bloom's Taxonomy, in increasing complexity, are knowledge, comprehension, application, analysis, synthesis, and evaluation. A summary of the MECH 223 knowledge-skillsjudgment taxonomy is given in Table 2.

As shown in Figure 2, each module in the course progresses with first the acquisition of knowledge, followed by the training of skills, and finishing with the development of engineering judgment.

The three-stage learning taxonomy also guides the evaluation process. Multiple choice questions and simple fill-in-the-blank questions are used on quizzes and exams to test students' knowledge. Short-answer questions and straightforward analyses are used to determine students' skill development. Complicated open-ended problems and essay-style questions are used to develop and assess students' engineering judgment.

Historically, engineering courses at UBC followed a more traditional or conventional approach which concentrated largely on developing the relevant knowledge and skills; the key vehicle for learning in most classes was the problem sets and, while we hope that students would develop some engineering judgment, we rarely gave them structured opportunities to do so. In contrast, with TBL, extended assignments that aim at developing such judgment are a central feature.

Table 2. MECH 223 Learning Taxonomy

\begin{tabular}{|c|c|c|c|}
\hline Category & $\begin{array}{l}\text { Behaviour } \\
\text { Descrip- } \\
\text { tions }\end{array}$ & $\begin{array}{l}\text { Relevant } \\
\text { Activities }\end{array}$ & $\begin{array}{l}\text { Eval. } \\
\text { Method }\end{array}$ \\
\hline Knowledge & $\begin{array}{l}\text { Recall or } \\
\text { recognize } \\
\text { information } \\
\text { Understand } \\
\text { meaning }\end{array}$ & $\begin{array}{l}\text { Individual } \\
\text { readings; } \\
\text { RAP } \\
\text { quizzes; } \\
\text { tutorial } \\
\text { exercises }\end{array}$ & $\begin{array}{l}\text { Multiple } \\
\text { choice or } \\
\text { fill-in- } \\
\text { the-blank } \\
\text { questions }\end{array}$ \\
\hline Skills & $\begin{array}{l}\text { Use or } \\
\text { apply } \\
\text { knowledge; } \\
\text { solve a } \\
\text { well-stated, } \\
\text { close-ended } \\
\text { problem }\end{array}$ & $\begin{array}{l}\text { Tutorial } \\
\text { exercises; } \\
\text { in-class } \\
\text { exercises; } \\
\text { assignment } \\
\text { arcs; } \\
\text { projects }\end{array}$ & $\begin{array}{l}\text { Short- } \\
\text { answer } \\
\text { questions } \\
\text { Simple } \\
\text { analyses } \\
\text { and tasks }\end{array}$ \\
\hline Judgement & $\begin{array}{l}\text { Solve an ill- } \\
\text { defined or } \\
\text { open-ended } \\
\text { problem; } \\
\text { select the } \\
\text { most } \\
\text { effective } \\
\text { solution }\end{array}$ & $\begin{array}{l}\text { Assignment } \\
\text { arcs; } \\
\text { discussions } \\
\text { and } \\
\text { debriefings; } \\
\text { projects }\end{array}$ & $\begin{array}{l}\text { "Engi- } \\
\text { neering } \\
\text { essay" } \\
\text { questions } \\
\text {; open- } \\
\text { ended } \\
\text { long- } \\
\text { answer } \\
\text { problems }\end{array}$ \\
\hline
\end{tabular}

To us, judgement refers to the ability of the students to apply their knowledge and skills to relatively openended problems where disagreements on the best answer are likely to occur across the class. To develop this ability, we regard it as essential that students have an opportunity to form their own opinion, to commit themselves to their position, and then to defend it in class and test it against the comments of their classmates and professors. The exercises in which students develop judgment are typically structured as extended assignment arcs which includes both out-ofclass individual preparation time and in-class team time.

While we have found it exciting to create these extended assignments, we have also learned that it is challenging to design them effectively. Before describing these challenges in more detail, we will first present an example of an entire module used in this course, with specific reference to the knowledgeskills-judgment taxonomy, so that one can see how an extended assignment fits into the overall educational strategy. 


\section{Example Module}

We now present an example of a module called the 'Mechanism Crash Course' (Module 3 from Table 1). This module occurs approximately one third of the way through the course and is designed to introduce students to the 'mechanism toolkit' used by mechanical engineers. That is, its purpose is to get students a quick introduction to the range of devices that mechanical engineers work with. The point is to give them exposure rather than analytical competence; the latter will be addressed in later years.

The module runs over a week and a half. Key elements are a reading assignment, two tutorial sessions, some interactive class time, and two major activities - a mechanism disassembly exercise (an inkjet printer), designed to bring students face-to-face with a real machine, and a mechanism design challenge, in which students are asked to pull together the knowledge they have been acquiring and apply it to the design and costing of a simple but realistic mechanism. The general schedule for this module is as follows:

\begin{tabular}{ll}
\hline Day & Activity \\
\hline- & Individual readings \\
\hline Friday & $\begin{array}{l}\text { Readiness Assessment Process (quiz) } \\
\text { based on readings }\end{array}$ \\
\hline Monday & Tutorial - Constraint identification \\
\hline Tuesday & Tutorial - Component familiarization \\
& and selection - students select \\
& components for a simple machine and \\
& use catalogs to estimate price \\
\hline Tuesday & Mechanism Intro (2h) \\
& - classify components by functional \\
& category (individual scorecards) \\
& - brainstorming to list additional \\
& mechanical components \\
& - key physics of several classes of \\
& components \\
& - constraint analysis of \\
& coupling/supporting components \\
& - hand around components \\
\hline Thesday & $\begin{array}{l}\text { Mechanisms 2 (1h) } \\
\text { - Introduce disassembly exercise } \\
\text { - Introduce mechanism design } \\
\text { challenge (more complex machine) } \\
\text { - Start work on mechanism design } \\
\text { challenge }\end{array}$ \\
\hline Printer Disassembly (2h) \\
\hline Tutorial - Preparation for design \\
challenge
\end{tabular}

There are additional classes and tutorials in this module on material selection, tolerances and fits, and technical communication skills, but because these do not relate directly to the extended assignment (design challenge), we will not discuss them in any detail. In the following sections, we will explain in more detail how the readings, tutorials, and in-class activities contribute to preparing the students for the mechanism design challenge that is the highlight of this module.

\subsection{Readings}

Prior to any tutorial or class time in this module, students are required to do some preliminary reading. The readings are drawn from a wide variety of sources as it is difficult to find an integrated presentation of a wide variety of mechanisms at an introductory level. Students are encouraged to skim through the readings to get a sense of what's involved; they are told that the RAP quiz on these readings will be based more on recognition than detailed application. Many of the students will likely be familiar with many of these devices anyway - they can use this opportunity to look for terms they don't know or to spend some time learning about the advantages and disadvantages of some mechanisms they're not familiar with.

We introduce students to the purpose of the various mechanical components by describing to them the design of a 'generic machine', as shown in Figure 3, and organize the discussion of components presented in the crash course according to these functions.

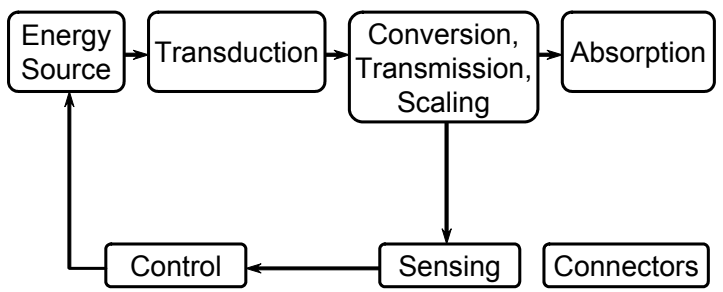

Figure 3. Generic machine

As mentioned above, it is difficult to find appropriate reading material for this subject. Much of what is available is pitched to the expert designer and is too detailed. We have therefore assembled some readings from a "How Things Work" perspective (brief intro to the different kinds of systems), some from texts (to give a brief overview) and some from parts catalogues (to give students a sense of the range of materials out there and the kind of information that usually is provided by the manufacturer). The primary purpose of this reading assignment is to ensure that the students recognize the different types of components and understand their relative strengths and weaknesses. The following list briefly describes the readings and provides some sense of what the students 
are asked to pay attention to at this stage (note: 'Norton' and 'Shigley \& Mischke' refer to two common mechanical engineering design textbooks).

\section{Power Supply, Transduction \& Absorption:}

- Norton - overview of actuators ( $\sim 6$ pages) good, quick description of $\mathrm{DC}$ and $\mathrm{AC}$ motors, pneumatics and hydraulics, solenoids

\section{Power Transmission \& Scaling:}

- $\quad$ Shigley and Mischke - intro to belts \& chains (portions of $\sim 5$ pages) - concentrate on the highlighted parts; ignore the rest for now

- $\quad$ The Way Things Work - gears and belts (2 pgs - does a good job of introducing the different kinds of gears and some representative applications.

- Norton - a brief description of four bar linkages ( $\sim 4$ pages $)$ - focus on the pictures as examples of real-life applications of linkages; disregard the text.

3. Supporting and Connecting Parts:

- $\quad$ Stock Drive Products Parts Catalog - (18 pages - mainly visuals) - quickly scan these pages to get a sense of the variety of parts used to build machines. We've highlighted the important sections of many of the pages, so there's actually much less than 18 pages' worth of content. When there is some text highlighted, students are asked to read it not for detail, but just for the issues raised.

We also provide some recommended readings:

- $\quad$ The Way Things Work (TWTW) - overview of actuator technologies (electric motor \& pneumatics \& hydraulics - lots of illustrations.

- How Things Work - 9.5 Electric Motors more detail than Norton

Finally, we point out some of the electronic resources available to them; the following are two examples:

- Illustrated Sourcebook of Mechanical Components - a great collection of wellknown ways to solve many mechanical design problems

- The Mechatronics Handbook - Chapter 20: Actuators (motors, pneumatics, hydraulics, MEMS)

\subsection{Tutorials}

Once the students have finished their readings and taken the RAP quiz, they are ready to work on some basic skills. In a previous module, they had been introduced to the notion of degrees of freedom and constraint. Since an important part of machine design is figuring out which parts move relative to which other ones, it is very helpful at the outset to have them understand what constraints one part applies to another. They are therefore asked to spend their first tutorial period looking at a variety of common 'connector' elements such as bearings, casters, flexures, U-joints, splines, and couplers and deciding how each component constrains the relative motion of the parts to which it is attached.

By their second tutorial, the students have encountered in class a wider variety of mechanical components and have had a whirlwind mini-lecture on the major sizing considerations of some key classes of mechanical components such as bearings, gears and belts (the class structure will be described in the next section). In this second tutorial, they are asked to perform a relatively realistic though quite simple design task - to specify components to be used in the drive train for a large ink jet printer. Although this may sound like a problem more suitable for developing judgement than skill, the problem's scope is sufficiently limited so as to ensure that the majority of teams will be able to successfully complete the exercise in the one hour they have available.

From a functional perspective, the problem comes down to identifying machine elements which will transmit rotary motion from the vertically mounted drive motor to the horizontally moving print carriage. The students therefore consider several options such as pulleys, belts, gears or various kinds of chain drives and must consider functional implications such as the need for a synchronous (positive) drive rather than one that can allow slippage. Once they have identified components which they believe will be able to perform the task, they must use simple physics to estimate the size of the loads that will be applied to the components and thus be in a position to select an appropriately sized component from a catalog.

In addition to addressing the key learning objective of gaining familiarity with common mechanical components, students also learn how to specify components from a parts catalogue and begin to gain some intuition for the relative costs of different components. Secondary learning objectives include having the students become accustomed to integrating course concepts in a single design problem and 
acquainting them with the style of the design challenge to come.

In this module, there are three additional tutorials which introduce students to material selection, tolerances and fits, and making oral presentations.

\subsection{In-Class Assignments}

The students come to class after the first tutorial exercise described above. Our goals in this first class are to broaden their exposure to mechanical components, to think about them systematically in terms of their function in generic machines, and to understand the basic physics which govern the sizing of each component.

In our teaching approach, we rely heavily on interactive techniques. For example, rather than tediously presenting slide after slide describing different mechanical components, we make a game of it. We give each student a computer scorecard and a list of 65 mechanical components. For each component, they have to determine which of the following five options best describes the component's primary function in relation to the generic machine:
A. Energy Supply
B. Transduction
C. Conversion, Transmission, Scaling
D. Absorption/Connection
E. Sensing/Control

The list of components runs from $\mathrm{A}$ to $\mathrm{V}$ (not quite ' $Z$ '!), as shown by the following selection:

1. Accelerometers

2. Air Blowers

3. Air Cylinders

4. Air Motors

5. Anti-backlash Gears

6. Ball Bearings

7. Ball Screws

8. Batteries

9. Brakes

10. Bushings

11. Cam Followers

12. ...

13. Sprockets

14. Tapered and Needle Roller Bearings

15. Threaded Rods

16. Thrust Bearings
17. Timing Belt \& Timing Belt Pulleys

18. Universal Joints

19. Valves

20. V-Belts \& V-Belt Pulleys

etc.

The computer scorecards can be rapidly marked and we can quickly identify the person or people in the class who have the best sense of what all these components are and do. We can also rapidly identify what the least familiar components are and spend a few minutes bringing everyone up to speed on them.

\subsection{Printer Disassembly Exercise}

Before asking students to design a machine, it is extremely helpful to have them take a detailed look at an existing machine and carefully observe how the various components they studied are used practically to achieve common mechanical functions. We therefore asked them to run through a two-hour exercise in which they disassemble a standard inkjet printer and fill in a 10 page workbook with a wide variety of questions about the various components that they are going to encounter. This is a high-energy activity with all members of the group typically gathered tightly around the printer trying to see exactly how each function is implemented. The students have the added pressure that they receive a grade of zero for the exercise if the printer is not returned in operating order. Overall, this exercise largely falls into the skill development category, although there are some evaluation tasks involved.

\subsection{Mechanism Design Challenge}

The true highlight of this module, however, is the mechanism design challenge. This exercise runs over several days, and students have two tutorial hours and a little over two class hours to complete the assignment, in addition to any individual prep work they do outside of class.

The purpose of this challenge is to give students an opportunity to apply their knowledge of the key components used in machines to the "quick ' $n$ ' dirty" design of a machine for a particular purpose. They are asked to evaluate some of the main design trade-offs between different approaches and to go through basic sizing and pricing calculations. The challenge culminates when they present key aspects of their design in class and try to prove that their design fully achieves the objectives at a lower cost than any other team's design. Their mark for the assignment depends on their ability to prove to the rest of the class that their design is in fact less expensive than any other competing design, so everyone is highly motivated to 
try to prove that the team claiming the lowest cost made errors in their design.

\subsubsection{Learning Objectives of the Challenge}

For this challenge, the primary judgement-based learning objectives was to integrate the knowledge and skills about mechanical components and mechanisms they had acquired earlier through the design, evaluation, and presentation of a complete mechanical design. Some of the more specific skill-based learning objectives were to:

- $\quad$ Identify the degrees of freedom of a proposed mechanism

- Select a set of constraining connections (based on normal contacts, ball-and-socket and rod connections, pin joints and flexural connections) between two parts that allow the desired relative degrees of freedom

- Estimate the size of selected common mechanical components given their basic loading conditions - eg, bearings, gears, shafts, keys

- Use intuition and quick graphing to generate rough shape of linkage to modify driving behaviour

- $\quad$ Find the cost of parts used in a machine

- $\quad$ Practice presenting your engineering designs and design reasoning to a technical audience of your fellow engineers.

\subsubsection{The Scenario}

We set the scene for the design challenge as follows: Multiple Sclerosis (MS) is a debilitating neural disease that attacks the patient's nerve fibres. Patients typically experience progressive muscle weakening due to an inability to properly fire and control their nerves. Exercise can slow the progression of the disease, but the best exercises are done on the floor and patients often lack the strength and coordination to lower themselves from their wheelchairs to the floor and lift themselves back up. There is, therefore, a need for a device which could attach to the wall of a house and provide a seating surface (approximately $40 \mathrm{~cm}$ x $40 \mathrm{~cm}$ ) which would lower and raise a seated patient (they can slide sideways from a wheelchair to another seat). The seat height of the wheelchair can be taken to be $45 \mathrm{~cm}$ and the seat must be lowered to within $10 \mathrm{~cm}$ of the ground. Patients will be unable to supply enough energy through any muscular action to effect this change in height, so the mechanism will likely have to be powered in some way.
This problem could obviously be solved in many different ways. For the purpose of this design challenge, we assume that some kind of scissor-type mechanism will be used, as sketched below:

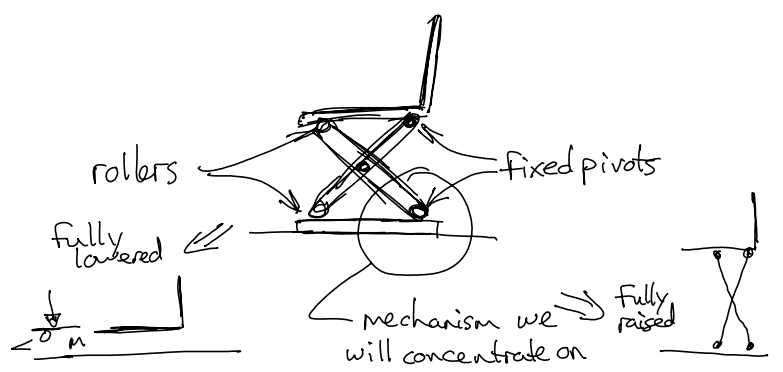

Figure 4. Sketch of design challenge situation

Students are encouraged to start by ignoring most of the details of the overall mechanism and concentrating on the issue of actuating the bottom rocker (circled in Figure 4). If they do a free-body diagram, they find that the torque required to lift the chair is equivalent to the vertical load acting at the tip of the rocker. A couple of reasonable possibilities for applying torque to the rocker are with electric motors or pneumatic actuators, although they are certainly encouraged to come up with others.

\subsubsection{Details of the Challenge}

The students' challenge is to design the lowest cost complete mechanism that can accomplish this task using one of the two basic actuation approaches suggested or other alternatives that they might propose. They are asked to consider variations in configuration - eg, they do not have to mount the motor directly in line with the pin, as shown in a sketch on the instruction sheet, but can offset it and use a transmission, or they can use a linkage in combination with either kind of actuator to shape the mechanical advantage they get through the range of motion (note that with the sketched design, the torque required will be greatest at low angles and least at high angles of $\theta$ ). Note also that in the lowered position the distance from the floor to the top of the seat should be less than $10 \mathrm{~cm}$.

On the first day that the design challenge was issued, students have approximately half an hour to work with their teams to go through a concept generation process and come up with their initial design. They then have two weekdays and a weekend to think about the problem individually, and on the Monday and Tuesday of the following week they have two tutorial hours and two class hours to work out the details and refine their design. During these 4 team hours, it is helpful for each team to have a laptop computer available to them for looking up specific 
part and price information on web sites supplying both (notably McMaster-Carr and Small Parts). Fortunately, it appears that roughly $15-20 \%$ of our students bring laptops to class regularly, so we were able to ensure that this was the case.

\subsubsection{Writeup}

The final class hour of the module is reserved for a whole-class debate. Prior to that class, each team is required to prepare a 2-3 page writeup showing:

- $\quad$ Estimated price of their design

- Clear sketch(es) of their proposed system with all parts numbered

- A parts list with 5 columns: catalog part number, part name, supplier, price, main selection criterion (e.g., radial load for a bearing)

- A brief rationale for their main design choices

- A brief presentation of their main sizing calculations

It is an important precept of team-based learning that any material handed in be relatively short; otherwise, the documentation work tends to be offloaded to one of the team members and it does not serve the purpose of stimulating mutual discussion and knowledge sharing.

Each team is also expected to prepare one or two overheads to illustrate their design concept and principal sizing calculations. They are encouraged to be concise primarily because a number of teams have to have the opportunity to make at least some portion of the case for their own design, but also because their peers can be a very tough audience - they are easily bored if a presentation drags on, and perceiving this response encourages the presenters to think more carefully about how to present their work.

\subsubsection{Debate}

At the beginning of the debating hour, teams place Post-it notes with their team number and estimated price on the front wall of the class; these are to be ordered in two or three rows by actuator type, but more importantly by price - lowest on the left, highest on the right. This immediately raises the interest level in the classroom because the team that posted the leftmost Post-it note is implicitly claiming to have come up with the best design. One or more representatives from that team are then invited to present their design, following which the other students are allowed to critique it. The two principal grounds of critique are:
- The design is incomplete, or

- The design is faulty (ie, will not work).

If either of these conditions are met, the Post-it note is shifted to the extreme right hand side of the board and the team can later argue that it should be moved further leftward.

During the class discussion, we (the professors) note down any features or good points made. These characteristics are summarized and passed on to the TA's for use in marking the writeups. The final mark for the student teams is a combination of the mark they receive on the write-ups from the TA's and the final justified cost following the critiques of the other students.

\section{Observations and Lessons Learned}

We have now run this module for two years and have taken the opportunity to refine it based on lessons learned the first time through, as well as lessons learned with several other extended assignments from other modules. In this section, we discuss some of our observations about what has worked well, where we have been too ambitious, and what has not proven to be particularly helpful.

\subsection{Assignment Design Theory}

A key tenet of team-based learning is that the most productive and integrative group discussion occurs when teams are forced to reach a single, unambiguous decision. Examples in the team-based learning literature from other domains of study include where to site a new drycleaning store (commerce) or what the most atypical example of a particular plant species is in a meadow (botany). A team's decision must commit them to a position that they will have to defend in discussions with other members of the class, so all teams must work on the same problem at the same time; it does not produce nearly as much discussion if different teams are assigned different tasks (for example, if each team in the commerce example above had been given a different kind of store to investigate). Finally, each team must report their results essentially simultaneously so that they cannot change their minds after another team has spoken but before they have presented their own conclusion. The fact that they have publicly committed themselves to a particular position increases their investment in making their case to the whole class.

\subsection{Experience - Things That Went Right}

In the mechanism design challenge described in this paper, many things went right. Students clearly 
enjoyed the range of activities in this module, particularly the printer disassembly exercise, and he remained engaged and animated throughout the tutorials and class time of the design challenge itself. For the most part, the teams worked very well together and there were virtually no indications of students being cut out of their team or of teams trying to have just one or two individuals solve the problem. Some groups did occasionally find it useful to divide into two subgroups in order to make some progress in parallel before tying the two components together again - this behaviour was encouraged. The technique of using Post-it notes to simultaneously report the results of the design process also worked very well, with various expressions of triumph or disbelief clearly audible as the notes went up on the board; this clearly primed the students for the upcoming discussion. During the debate itself, students were generally quite respectful of those students who came to the front of the class to present their designs, but nonetheless asked many insightful questions about the designs presented and took some obvious pleasure in knocking out the front runners when they were able to do so.

\subsection{Lessons}

Naturally, there is room for improvement. For example, we discovered that teams often need experience and explicit coaching in how to work effectively as a team. Some of the proponents of team-based learning argue that the structure of teambased learning assignments intrinsically promotes proper team functioning. We believe that while properly designed assignments certainly reward wellfunctioning teams, sometimes students seem to not understand how to recognize when tasks can be effectively divided so that they could progress in parallel; a number of times, particularly when someone was looking up pricing information on the team's laptop, several other key members seemed to be waiting around rather than working on calculations, drawings or documentation.

We also found that, while the debate class was generally engaging, the focus was certainly on the teams that claimed the lowest costs. Occasionally, a team which claimed a higher cost would present the justification for their design and ask the teams with lower costs to prove that they had included all the components of the more expensive team that included, the 20 teams in the class, it was difficult for more than half of all the teams to have contributed at all to the class discussion. Part of the answer to this may be to extend the debate, but this has the disadvantage of there only being one person speaking at a time.
Perhaps the ultimate solution would be to have the class subdivided into three or four groups such that each team in the subgroup would have a chance to discuss their own design with the other teams, although it is helpful for the professors to hear what the teams say in their presentations.

When we originally designed this mechanism design challenge, we had in mind a much more complex evaluation protocol. We (ie, the professors) had intended to assign marks to each team based on what they presented in class, but not to reveal our opinions to the students. We would then ask each team to identify which team they thought had the best design and would assign bonus marks to teams which made judgements similar to ours (ie, rewarding good judgment), as well as to teams which attract votes (ie, rewarding convincing presentations). However, because not all the teams could present their designs, not even all of the top five, this scheme turned out to be impractical. Nonetheless, we like the idea of structural incentives for students to make good presentations and to speak out during the debate period, so we will continue to consider how to make such an evaluation scheme work in future assignments.

We have observed some interesting variations in student response between the two years. Last year, there was a significant lack of buy-in for the mechanism design challenge assignment. Students felt that it was a distraction from their primary project and did not perceive much independent value. In retrospect, we had provided too little in-class time, which meant that in effect it became a homework assignment at a time when they had no slack in their schedule. We rectified that this year by providing more class hours and by tying it much more tightly to the explicit learning objectives and curricular goals.

Finally, there was one puzzling change from last year to this related to a different extended assignment which focused on assessing uncertainty in the design process. As with the mechanism design challenge, last year's students had comparatively little time for this uncertainty assignment, but they nonetheless did an excellent job with it. One of the other comments we received about it was that the students did not feel they had an adequate understanding of basic statistical concepts such as mean and standard deviation, so this year we rectified both problems - we added readings and a tutorial on basic statistics, spent some class time on a slightly more complicated problem, and added almost 2 hours to be in class time associated with this assignment. Despite all this, this year's class did considerably less well on the extended assignment. We are puzzled about this, but have speculated that 
perhaps last year's class knew they were being challenged and rose to the challenge, whereas perhaps this year's class was initially expecting more guidance through the problem and gave up when it became unexpectedly difficult. To us, this indicates that paying attention to the students' fundamental attitudes towards the assignments and potentially trying to modify their attitudes rather than the assignments may be the way to address this issue.

\section{Conclusions}

Overall, students enjoyed the format of the revised Mech 2 curriculum very much, and in particular they preferred the team-based learning approach of Mech 223 by a wide margin over conventional core structures. As professors, we have been impressed by the quality of the collaborative work that the teams do on these extended assignments, and we believe that they are serving their intended function of developing the students' ability to make engineering judgements. Over the first two years of this new curriculum, we have applied a variety of assignment design principles to several extended assignments and now have a more nuanced view of what tasks will work well in our current large class setting. We look forward to updating and improving our assignments again next year in the light of our continuing experience.

\section{References}

[1] Michaelsen, L.K., A.B. Knight, and L.D. Fink, TeamBased Learning: A Transformative Use of Small Groups in College Teaching, Stylus Publishing, Sterling, VA, 2004.

[2] Hodgson, A.J., P.M. Ostafichuk, and J. Sibley, "TeamBased Learning in the Design Modules of a New, Integrated, 2nd Year Curriculum at UBC", Proceedings of the 2nd CDEN International Design Conference, Kananaskis, AB, July 18-20, 2005.

[3] Bloom, B.S., M.D. Engelhart, E.J. Furst, W.H. Hill, and D.R. Krathwolh, Taxonomy of Educational Objectives, David McKay Company, New York, 1956. 